\title{
O ENSINO DE HÍBRIDO NAS AULAS DE HISTÓRIA NOS ANOS FINAIS DO ENSINO FUNDAMENTAL: IMPACTOS E TRANSFORMAÇÕES NO PROCESSO DE APRENDIZAGEM
}

\author{
HYBRID TEACHING IN HISTORY CLASSES IN THE FINAL YEARS OF \\ FUNDAMENTAL EDUCATION: IMPACTS AND TRANSFORMATIONS IN THE \\ LEARNING PROCESS
}

Samanta Trivilin Comiotto ${ }^{1}$

\begin{abstract}
RESUMO: As rápidas mudanças que ocorrem na sociedade atual levam a escola a repensar suas práticas para adequar-se a modelos cognitivos que se encaixem as necessidades sociais exigidas aos sujeitos pertencentes a ela. Neste sentido, as metodologias do ensino híbrido trazem novas possibilidades para a produção do conhecimento e para a significação da aprendizagem dos educandos "nativos virtuais". Unir o ensino de história que, possui em seu caráter primeiro, o objetivo de formar cidadãos pensantes e atuantes na sociedade com base na análise das ações humanas ao longo do tempo, a novas formas de significar o passado podem contribuir para um processo de aprendizagem de maior qualidade e relevância.
\end{abstract}

Palavras-Chave: Ensino híbrido. História. Aprendizagem.

\begin{abstract}
Fast changes that are happening in nowadays society make the school rethink its practices in order to adapt itself to cognitive models that fit the social needs demanded to the people belonging to it. In this sense, the methodologiesof hybrid teaching bring new possibilities to the knowledge production and to the learning significance for the "virtual native" students. By unifying History teaching, which teh main purpose is to form thinking and active citizens in the society, based on the analysis of human actions over time, to new ways of meaning the past contribute to a learning process of higher quality and relevance.
\end{abstract}

Keywords: Hybrid teaching. History. Learning.

1 Mestre em História pela Universidade do Vale do Rio dos Sinos - UNISINO. Técnico-administrativo no Instituto Federal de Educação, Ciência e Tecnologia do Rio Grande do Sul- IFRS, Campus de Veranópolis. 


\section{Introdução}

A educação como um todo passa por momentos de mudanças e transformações no seu pensar teórico e na estruturação de seu sistema de ensino. As novas ideias que se vinculam a abordagens diferenciadas quanto as maneiras de ensinar passam, de forma lógica, pelo processo de aprender. Como afirma Freire (1996, p. 24), "aprender precedeu ensinar ou, em outras palavras, ensinar se diluía na experiência realmente fundante de aprender". Sendo assim, o fazer docente precisa, necessariamente, estar em constante ligação ao aprimoramento de estratégias para o processo de ensino-aprendizagem que possam elevar a prática do aprender e descentralizar a prática do ensinar como fonte primordial neste processo. O que se pode perceber é a eminente necessidade de a escola adequar-se às mudanças sociais, deixando de reproduzir formatos peculiares do século passado. A instituição escola passou, ao longo da história, por momentos de adaptação correspondentes a visão de formação de cidadão para o mundo do trabalho. Isso aconteceu nos processos que envolveram as chamadas Educação 1.0 e a Educação 2.0². Como coloca Lengel,

educação e ambiente de trabalho correspondiam exatamente um ao outro. A escola produzia os tipos de cidadãos necessários ao mundo ao seu redor. Cidadãos capazes de trabalhar bem e em grupo pequeno, com ferramentas manuais, realizando uma variedade de tarefas todos os dias, com uma visão clara do mundo lá fora e um pequeno círculo de conexões (LENGEL, 2017, p. 47).

Neste sentido, é possível observar que, as aprendizagens escolares estavam ligadas ao trabalho na terra com o uso de instrumentos simples em um ambiente de conhecimento que transpassava gerações e chegava à escola. Aí está a chamada Educação 1.0. Com o aparecimento das fábricas mudanças no ambiente escolar também ocorrem: a repetição de tarefas, em silêncio, e a supervisão direta do seu trabalho passaram a acontecer e, assim, as escolas mudaram para atender os requisitos de formação trazidos pela indústria. Segundo Lengel,

2Conceitos utilizados por James G. Lengel (2017). 
os alunos formavam grupos maiores, todos da mesma idade. Ficavam fechados em salas e trabalhavam segundo o ritmo das horas. Usavam ferramentas mecânicas, lápis e papel. Todos faziam a mesma coisa, ao mesmo tempo. Eram supervisionados de perto. Vamos chamar de Educação 2.0 (LENGEL, 2017, p. 48).

E, hoje, como são nossos ambientes de trabalho? Como se apresenta esta ligação entre mundo do trabalho - escola? Na atualidade, a tecnologia se apresenta como ferramenta de produção, são exigidas novas habilidades para o trabalho em grupos, com o incentivo a novas ideias, a criatividade, a resolução de problemas, a pro-atividade. E a escola, se modificou para acompanhar a formação destes cidadãos? Para Soares e Luchese

[...] o que sobressai ainda é esse layout tradicional, com professor à frente dos alunos, que organizados em fileiras e algumas vezes em pequenos grupos, ouvem o discurso e as explicações do professor. Ou seja, independente da estratégia, em geral o professor coloca-se como o detentor do conhecimento, o qual é transmitido ao aluno na forma de conteúdos e informações (SOARES; LUCHESE, 2015, p. 499).

O que temos, é a manutenção das práticas de ensino da Educação 2.0 em uma sociedade que evoluiu e já vive um sistema produtivo 3.0. Ou seja, práticas educativas precisam ser adaptadas e a Educação 3.0 necessita acontecer.

A educação "bancária"3, voltada para o mundo fabril, não corresponde mais às necessidades de formação dos cidadãos do século XXI, para o convívio em sociedade e para as relações de trabalho que precisarão vivenciar. Buscar uma reprodução de ideias, uma cópia fiel a conceitos e uma decoreba de datas e fatos não traz os resultados esperados para o desenvolvimento de habilidades e competências exigidas pela sociedade atual. Neste sentido, é que a busca por uma educação de qualidade se torna urgente. Segundo José Moran (2017, p. 63), "a educação de qualidade, além de ensinar a pensar, pode ensinar a viver".

No papel de educadora no componente curricular de História do ensino fundamental anos finais, vivencia-se esta necessidade de mudança da prática docente nas aulas ministradas. A falta de atenção, de interesse e de

3Termo utilizado por Paulo Freire. 
comprometimento repercute a inconsistência entre a vida fora e dentro da escola. Perceber nas falas dos educandos seu conhecimento e interesse em jogos e em tecnologia é empolgante, mas, ao mesmo tempo, intrigante. Por que em aula esta postura de curiosidade e interesse não acontece? Como motivar os educandos para usar seus esforços para sua participação ativa em prol da aprendizagem em sala de aula? A partir desta reflexão, novas metodologias passaram a ser alvo de interesse e estudo como prática e dinâmica das aulas, em especial, as ligadas ao ensino híbrido.

Híbrido em seu conceito básico nos traz a ideia de mistura, de heterogeneidade. Neste sentido, pensar o hibridismo como estratégia para a sala de aula, abre diferentes caminhos para que a aprendizagem significativa chegue de forma mais contundente aos educandos. Pois nos propicia mesclar ambientes de estudo presenciais e online, adequar tempos e espaços de aprendizagem, a partir de atividades que desenvolvam habilidades de interação entre esses espaços de estudo. Coloca o educando em uma condição de protagonista deste processo, em que ele aplicará o conhecimento de variadas formas, trazendo novos significados aos conceitos científicos. O que possibilita, fazer a ligação entre a prática de vida e a ciência apresentada.

Nos anos finais do ensino fundamental, em especial, no componente curricular de História o educando passa a conviver com conceitos próprios da ciência histórica que o levam a formar argumentações e opiniões quanto a vida em sociedade. Deste modo, despertar nele a motivação para aprender se torna imprescindível para o sucesso no processo de obtenção do conhecimento. Em concordância com Fernando Becker (2017, p. 42-43), "a escola tem de ser um lugar onde o aluno vai para trabalhar, para agir, para experimentar, testar hipóteses, cooperar, conquistar autonomia". Nesta visão, as abordagens de novas metodologias vinculadas ao ensino híbrido no ensino de História propiciam possibilidades e estratégias para desenvolver habilidades e alcançar competências que levem os educandos a compreender a importância da História como conhecimento formador de cidadania, de reflexão e de argumentação sobre as questões que pautam o ser humano no decorrer do tempo e nos dias atuais. Oportunizar a ação de perceber-se como agente transformador de seu contexto 
social e de seu tempo histórico leva o educador a buscar novas formas de ensinar e aprender a História. Segundo Freire,

o professor que pensa certo deixa transparecer aos educandos que uma das bonitezas de nossa maneira de estar no mundo e com o mundo, como seres históricos, é a capacidade de, intervindo no mundo, conhecer o mundo. Mas, histórico como nós, o nosso conhecimento do mundo tem historicidade. Ao ser produzido, o conhecimento novo supera outro antes que foi novo e se fez velho e se "dispõe" a ser ultrapassado por outro amanhã. Daí que seja tão fundamental conhecer o conhecimento existente quanto saber que estamos abertos e aptos à produção do conhecimento ainda não existente (FREIRE, 1996, p. 28)

Talvez esta seja uma das maiores belezas que o aprender História possa nos levar a conhecer: a historicidade do conhecimento e a possibilidade de criá-lo como forma de o próprio ser humano se reinventar no tempo. Elucidar a relevância do conhecimento histórico nas nossas vidas é que nos faz abrir nossas mentes e refletir sobre os caminhos que iremos trilhar. Dessa maneira, resgatar esta visão faz parte do processo de remodelar o ensino da História e trazer novas práticas de construção do conhecimento em sala de aula e fora dela.

O ensino de História possui expressiva relevância no processo de formação de cidadãos capazes de agir, interagir e construir relações sobre as questões do passado e do seu tempo presente é que a discussão teórico-metodológica da prática docente se torna necessária. Como fundamentam Gil e Almeida (2012) é desafio hoje ensinar História a partir de diferentes pontos de vistas, sem a pretensa verdade ou versão única dos fatos, seja do livro didático ou da explicação da professora. Em concordância com estas ideias é que, busca-se analisar de forma mais atenta e detalhada novas formas e métodos de trazer a História para mais próximo do educando e permitir-lhes possibilidades de se perceber como agente transformador de seu tempo histórico. Como afirma Gil e Almeida,

ensinar História é construir estratégias para que as crianças encontrem respostas às suas perguntas e, a partir delas, formulem outras, acessem informações, reflitam sobre elas e produzam escritas que as organizem, ampliando os sentidos de suas problematizações (GIL; ALMEIDA, 2012, p. 25). 
Nas relações que se estabelecem no cotidiano da escola, a busca pelo conhecimento perde seu objetivo de despertar para novas descobertas quando os agentes da docência apresentam descrições de fatos que parecem estar muito distantes da realidade que o educando vive e de seus interesses pessoais. Mostrar que o passado não é estático, mas sim, que possui dinamismo e inúmeras alternativas para sua construção e pesquisa é o desafio da Educação 3.0.

Não obstante, este é o desafio do educador de História. E é neste momento que indagações pedagógicas surgem, no sentido de como traçar este trilho de mudança, de como oportunizar aos educandos novas visões do passado e de sua escrita e de como proporcionar a eles novos horizontes para construção da própria história. Para isto, um dos possíveis caminhos que direcionem para a dinamização do processo de ensino e de aprendizagem, versa sobre a busca por metodologias que os estimulem a pesquisa, a interação com o conhecimento e o encontro com significados concretos para os saberes aprendidos.

A partir de experiências vivenciadas na sala de aula com educandos de $6^{\circ} \mathrm{e}$ 70 anos é que algumas mudanças quanto a aprendizagem puderam ser constatadas. $E$, estas mudanças, vieram em decorrência da inserção da prática do hibridismo e das metodologias ativas na sala de aula. As metodologias ativas, por sua vez, fazem do educando o protagonista, o centro no processo do aprender, pois os levam a colocar em prática o conhecimento científico por meio de produções, projetos e experiências que, combinam e integram variados métodos propulsores do ensino e da aprendizagem significativa. Como coloca Moran (2017, p. 71), "ênfase no aprender fazendo, na cultura "maker": aprender a partir de projetos reais, problemas significativos, histórias de vida, jogos". As metodologias ativas mesclam com as tecnologias digitais novas estratégias de protagonismo para o educando.

Uma destas estratégias propiciadas pelas metodologias ativas é a aula invertida. Neste método, o educando transita entre o espaço online e o presencial, fazendo uso de materiais digitais diversos, como vídeos, imagens e materiais físicos como os livros, por exemplo. Neste contexto, é que os educandos ingressaram num processo de inversão de compreensão e alcance do conhecimento, demonstrando assim que, a adaptação a metodologia da aula 
invertida é uma possibilidade real de inovação. Segundo Bergmann e Sams (2017, p. 12) "deixamos de ser meros transmissores de informações; em vez disso, assumimos funções mais orientadoras e tutoriais". Utilizando de vias de aprendizagem fomentadas nas aulas invertidas, é possível trazer o educando para o centro do processo educativo e por meio do uso de vídeos, pesquisa, análise, produção e argumentação de temas históricos abrir possibilidades em diferentes escalas. Nesta perspectiva, abrem-se oportunidades de o educando aprender sozinho, aprender em grupo e aprender com o professor.

Em corroboração a esta experiência, constatamos que diversos são os trabalhos acadêmicos que estão sendo produzidos e que envolvem as metodologias do ensino híbrido e do ensino de História como temas de pesquisa com resultados positivos de sua implementação no espaço escolar. Fator que nos proporciona transitar por vias mais abrangentes do trabalho pedagógico e que nos apresenta possibilidades de dialogicidade entre a produção acadêmica e científica e a prática docente que embasa o cotidiano escolar e suas aprendizagens.

Nesta perspectiva de nosso diálogo teórico-metodológico com a academia, citamos, a tese $A$ história, seu ensino e sua aprendizagem: conhecimentos prévios e o pensar historicamente de Daniel V. Helene (2016), que pesquisa como os alunos constroem ideias mais complexas a partir do pensar historicamente; a dissertação de Noemi Maria (2012) O currículo e o ensino de história nos anos finais do ensino fundamental que, por sua vez, discute a importância dada pelos alunos ao componente curricular de História e quais relações eles estabelecem entre o que se ensina na sala de aula e o que vivenciam socialmente; Ensinar e aprender história na relação dialética entre interpretação e consciência histórica crítica de Maria Cavalcante (2014) que relaciona a atividade docente a aprendizagem do educando no processo de apropriação de conhecimento utilizando a interpretação de textos históricos no $8^{\circ}$ ano do ensino fundamental. E, também, estudos vinculados ao hibridismo, como Implicações da organização da atividade didática com uso de tecnologias digitais na formação de conceitos em uma proposta de Ensino Híbrido, tese defendida por Lilian Bacich Martins (2016) que, investiga como a atividade didática no ensino híbrido possibilita adequadas condições para a formação de conceitos; Formação de professores de educação básica para uso de linguagem híbrida: a importância do roteiro de audiovisual no 
processo de ensino-aprendizagem de Fernando Berlezzi (2017) que, discute a importância do educador no contexto de mudanças tecnológicas e a apropriação destes recursos como estratégia pedagógica para a condução de suas aulas; e, a dissertação de Iara Yamamoto (2016) Metodologias ativas de aprendizagem interferem no desempenho de estudantes, analisando o crescimento do desempenho dos estudantes a partir da exploração de novas oportunidades de aprendizagem presenciais e virtuais.

No encontro de respostas para nosso estudo de caso, especialmente, utilizamos como fundamentação metodológica obras que discutem o hibridismo como caminho para adaptar a sala de aula as exigências do mundo do trabalho e de formação social a que os estudantes se deparam nos dias de hoje levando-os a aprofundar conhecimentos e a uma aprendizagem de significado. Para isso, percorremos obras de Jonathan Bergmann e Aaron Sams, de Lilian Bacich, Adolfo Neto e Fernando de Mello Trevisani, de José Moran e os trabalhos realizados pelas instituições Fundação Lemann e o Instituto Península. Como vias de pesquisa das questões do ensino e da história, consideramos obras de Paulo Freire, de Mônica Timm de Carvalho, Circe Bittencourt, Carmem Gil e Dóris Almeida, Roger Chartier, Terciane Luchese, Idair Ecco e Carla B. Pinsky que, analisam o saber e, em especial a história, como um processo contínuo de crescimento em que o indivíduo transita por experimentações que possibilitam seu avanço cognitivo, emocional e social.

Seguindo esta base teórica cerceamos ideias que consideram os percursos da adaptação didática às metodologias ativas, ao contato presencial e virtual e o aprofundamento da aprendizagem histórica significativa como centro do nosso estudo. Assim, pensamos que inúmeras são as formas e as possibilidades de chegarmos ao conhecimento. A escola sempre proporcionou aos educandos experimentos para aprender em diferentes momentos e espaços. Contudo, nas últimas décadas, com a mobilidade e a conectividade, novos contextos se tornaram mais evidentes e caminhos mais profundos e criativos foram abertos. O que colocou o conceito híbrido em evidência. Segundo Moran,

podemos ensinar e aprender de inúmeras formas, em todos os momentos, em múltiplos espaços. Híbrido é um conceito rico, apropriado e complicado. Tudo pode ser misturado, combinado, e podemos, com os mesmos ingredientes, preparar diversos 'pratos', com sabores muito diferentes (Moran, 2015, p. 27). 
No livro Educação 3.0: Novas perspectivas para o ensino, os autores chamam a atenção justamente para estas mudanças que vivemos na sociedade atual, apresentando a eminente necessidade de mudança na educação para alcançar patamares maiores de qualidade da aprendizagem. Para Mônica T. de Carvalho,

na educação 3.0, contudo, o ensino só será tido como válido se impactar visivelmente os resultados de aprendizagem, pois essa perspectiva educacional entende que $o$ ato de ensinar pressupõe intervenções deliberadas para que mudanças cognitivas nos alunos sejam garantidas (CARVALHO, 2017, p. 110).

Neste sentido, a metodologia da sala de aula invertida também abre inúmeras possibilidades de acesso ao conhecimento e modifica a relação professor- aluno em sala de aula. Como destaca Bergmann e Sams (2017, p. 22) "acreditamos que a inversão cria condições para que os professores explorem a tecnologia e melhorem a interação com os alunos". Da mesma forma, a interação aluno - aluno também se modifica "eles passam a se ajudar, em vez de dependerem exclusivamente do professor como único disseminador do conhecimento" (BERGMANN; SAMS, 2017, p. 24).

Para Bacich, Tanzi Neto e Trevisani, "a integração das tecnologias digitais na educação precisa ser feita de modo criativo e crítico, buscando desenvolver a autonomia e a reflexão dos seus envolvidos, para que eles não sejam apenas receptores de informações." (BACICH; TANZI NETO; TREVISANI, 2015, p. 47). Estes novos caminhos metodológicos que são abertos aos educadores propiciam elevar o nível de aprendizagem dos educandos por meio da utilização de diferentes ferramentas que tornam as aulas mais significativas e profundas em análise.

Nesta conjectura educacional pensar o ensino da História a partir da mobilidade entre o físico e o virtual se torna importante. A História como disciplina humana, por si só, já carrega inúmeras possibilidades de se ler, interpretar, relacionar, analisar e argumentar, com base no passado, as questões que permeiam o ser humano ao longo do tempo. Segundo Luchese,

compreendo a história como processo que, em suas multiplicidades, descontinuidades, brechas e atravessamentos constitui os momentos do passado- presente. Penso a história como narrativa, 
como trama do passado, como fio que se intersectam na construção do passado, permeado por práticas e representações (LUCHESE, 2014, p. 147).

Contudo, para esta geração de "nativos virtuais", o passado, a documentação e os textos não despertam por si só o interesse no saber histórico. O que abre caminhos para a práxis híbrida como ferramenta de interação entre o passado e o presente. Como coloca Moran,

a aprendizagem é mais significativa quando motivamos os alunos em seu íntimo, quando eles acham sentido nas atividades propostas, quando consultamos suas motivações profundas, quando se engajam em projetos criativos e socialmente relevantes (Moran, 2015, p. 33).

O conhecimento histórico aprendido e ensinado nos anos finais do ensino fundamental traz ao educando embasamentos conceituais, temporais e espaciais das construções humanas levando a descoberta de novos olhares sobre o passado. A compreensão da importância do saber histórico e suas relações com o presente os cativam a construir suas próprias argumentações sobre os fatos e se perceber como sujeitos construtores da história. Chartier afirma em sua obra A história ou a leitura do tempo que a História é uma representação das ações humanas no tempo, uma forma de compreender o passado tentando chegar às formas discursivas e imagéticas pelas quais os homens expressam a si próprios e o mundo (CHARTIER, 2009).

A função do professor de História é fazer a mediação entre o educando e o conhecimento. Utilizar de metodologias diferenciadas, variar espaços de aprendizagem e levá-los ao contato direto com a história e sua produção por meio de pesquisas abrem caminhos para aprendizagens mais significativas. Segundo Idair Ecco,

a 'compreensão dos processos' e o 'desvelamento das realidades' são possíveis mediante situações didático-pedagógicas e/ou situações de aprendizagem para além do caráter reprodutivista, discursivo. É mister trabalhar na perspectiva problematizadora, com metodologias congruentes, apropriadas em relação à construção do conhecimento histórico, tanto no horizonte da pesquisa científica, quanto no âmbito do saber escolar. Desafiar constantemente é uma 
das características do ato de educar; do contrário, contribui-se para o obscurantismo, para o 'silenciar' de consciências (ECCO, 2007, p. 129).

A aula de História proporciona ao educando momentos de aprendizagem para construir sua visão de mundo e perceber-se como agente formador e transformador da realidade que o cerca para que possa ocupar efetivamente seu lugar de cidadão. Para Pinsky, (2010, p. 32) "capacitar os estudantes para perceber a historicidade de concepções, mentalidades, práticas e formas de relações sociais é justamente uma das principais funções das aulas de História." Este é um dos desafios do professor: apresentar ao educando a importância do estudo do passado e sua total relação com o presente. Como destaca Bittencourt,

o professor de História pode ensinar o aluno a adquirir as ferramentas de trabalho necessárias; o saber fazer, o saber fazer bem, lançar os germes do histórico. Ele é responsável por ensinar o aluno a captar e a valorizar a diversidade dos pontos de vistas. Ao professor cabe ensinar o aluno a levantar problemas e a reintegrálos num conjunto mais vasto de outros problemas, procurando transformar, em cada aula de História, temas em problemática (BITTENCOURT, 2012, p. 57).

Assim, consideremos a afirmativa de Freire "saber que ensinar não é transferir conhecimento, mas criar as possibilidades para a sua própria produção ou a sua construção" (FREIRE, 1996, p.47). Este é motor motivacional do processo de aprender e ensinar: propiciar ao indivíduo a descoberta de si mesmo e do mundo que o cerca num processo de mútuo aperfeiçoamento.

Como parte relevante deste estudo, realizamos uma breve descrição da experiência docente realizada que esteve fundamentada nas ideias conceituais abordadas neste artigo.

\section{Relato da experiência}

Inicialmente, queremos caracterizar o contexto escolar em que este estudo de caso foi realizado para uma melhor compreensão empírica do processo. A prática ocorreu em uma instituição de ensino que pauta pela ação docente baseada 
na visão tradicional da educação. Cerceada pela pedagogia conteudista e conservadora em que, a sala de aula tem como layout classes enfileiradas e educandos sentados, em silêncio, um atrás do outro. Aulas que buscam decorar, conceituar e analisar objetos de estudo em sua forma literal, embasados, na maioria dos casos, apenas na versão trazida pelo livro didático adotado. Assim, a dinâmica das aulas pouco instigam a criatividade, a autonomia na busca pelo conhecimento, a compreensão do porquê estudar estes temas, as relações entre o que se estuda e sua vida cotidiana e, em uma visão particular, deixam de priorizar, um dos aspectos mais relevantes, trazer o educando para o centro do espetáculo, para ser o protagonista do processo educativo.

Em virtude da inserção estudantil nesta realidade, para a experiência pedagógica a que nos propusemos, foi preciso iniciar e organizar as aulas a partir de um processo lento de mudanças paulatinas na dinâmica de sala de aula. As turmas de $6^{\circ}$ ano e 70 ano, foram conhecendo e explorando atividades das metodologias do ensino híbrido como primeiro contato com novas formas de aprender História.

Com o uso da aula invertida, uma nova rotina de estudos foi implementada. O assistir a vídeos em casa como forma prévia de acessar ao conhecimento e a resolução de situações-problema envolvendo o vídeo proporcionou aos educandos, uma inicial compreensão dos objetos de estudo a serem discutidos. Da mesma forma, puderam trazer para a aula questões e análises formuladas quanto a suas primeiras compreensões e as possíveis dúvidas que surgiram no estudo. Na sala, o trabalho em grupos, o acesso a diferentes fontes de pesquisa e atividades de aprofundamento dos temas históricos mudou o ambiente de convívio: as turmas que antes eram agitadas, distraídas e sem foco para a aprendizagem, passaram a trabalhar ajudando os colegas, em práticas de discussão de conceitos e de formulação de hipóteses do passado analisado o que permitiu atingir níveis mais complexos de estudo. Situação esta que nos propiciou melhor aproveitar o tempo das aulas com as produções e aprofundamentos em atividades do que com aulas meramente expositivas. Em concordância com Bergmann e Sams,

os professores de ciências sociais relatam que usam o tempo extra para discutir os eventos em curso, à luz do vídeo instrucional da noite anterior. Outros estão tendo condições para se aprofundarem 
na análise do documento original. Dessa forma, há mais tempo para debater, discursar, para se autodefender em tribunais pro se, pra debater o que os alunos estão aprendendo com mais profundidade, sem recear que uma conversa densa seja interrompida por uma campainha (BERGMANN; SAMS, 2017, p. 44-45, grifo do autor).

A metodologia da rotação por estação também foi implementada nas mesmas turmas e, novamente, após um processo inicial de adaptação, os resultados alcançados foram muito satisfatórios. Os educandos ficaram motivados a produzir pesquisas, a criar jogos de tabuleiro e digitais, a participar em atividades extraclasse, a montar grupos de estudo e produzir narrativas históricas mais detalhadas com informações mais aprofundadas dos temas estudados.

Além destas práticas metodológicas em sala de aula, foi possível mesclar espaços de estudo, distribuindo atividades em outras áreas da escola e, até mesmo fora dela, a partir da experimentação em oficinas de história, por exemplo. Em consonância a Glauco Santos (2015, p.106), "a escola precisa ser repensada com vistas a criar vários espaços onde o aluno possa aprender a partir de uma aula expositiva, uma roda de debate, uma leitura, etc., a fim de experimentar aquilo que aprendeu na teoria". A partir da abertura a novos espaços de aprendizagem e a diferentes metodologias, que estes educandos não tinham acesso anteriormente a este processo, como resultado, foi possível constatar que, as notas melhoraram e muitos educandos que apresentavam dificuldades nas habilidades de interpretação e em estabelecer relações entre conceitos progrediram bastante. Isto porque, os educandos adentraram a possibilidade de personificar seu estudo, gerenciando seu aprendizado de acordo com seu ritmo para o desenvolvimento das atividades que precisam realizar.

Outro fator de grande relevância nesta experiência foi o iniciar deste movimento de personificação do ensino. Como nossos educandos eram ingressos do $6^{\circ}$ ano e 70 ano, com pouco incentivo a autonomia aos estudos, já que as orientações e diretrizes para a execução das tarefas eram ditadas pelos educadores em uma mesma ordem para toda a turma, os educandos ficavam condicionados a realizar as atividades no mesmo ritmo. Com a abertura para a personificação, nossas turmas se mostraram abertas a gerenciar seu estudo, surpreendendo positivamente a educadora nos encaminhamentos das demandas 
solicitadas sem maiores dificuldades em atender as solicitações. Grupos de estudo se formaram e, com isso, monitorias foram instauradas durante as aulas, sendo que, os próprios educandos passaram a gerenciar se todos do seu grupo estavam realizando as tarefas adequadamente. Em acordo com Schneider (2015, p. 69), "personificar significa que as atividades a serem desenvolvidas devem considerar o que o aluno está aprendendo, suas necessidades, dificuldades e evolução - ou seja, significa centrar o ensino no aprendiz".

Um aspecto atitudinal que nos chamou a atenção durante o processo de implantação das metodologias ativas e dos espaços híbridos de estudo foi que, educandos anteriormente displicentes em sua postura quanto ao comprometimento e responsabilidade com seus deveres e tarefas de estudo passaram a demonstrar maior envolvimento em propostas de trabalho e em práticas de análise. Como descrito anteriormente, nas atividades em grupo, educandos passaram a monitorar uns aos outros como forma de melhor aproveitar o tempo em aula para a realização das atividades e para solucionar dúvidas. Realidade esta que vem de encontro com a afirmativa de Bergmann e Sams (2017, p. 24),

ao perambularmos pela sala de aula, nós testemunhamos a criação de seus próprios grupos de colaboração. Eles passam a se ajudar, em vez de dependerem exclusivamente do professor como único disseminador do conhecimento.

Por fim, cabe-nos apontar sobre a questão da avaliação. Entendemos a avaliação como um processo contínuo que acontece no decorrer de todo o processo de ensino e aprendizagem. Portanto, partindo dessa premissa, nossos objetivos foram traçados a partir das habilidades e competências que buscamos desenvolver com os educandos em cada objeto de estudo trabalhado. Utilizamos de provas formais, de atividades de pesquisa, de criação, de criatividade e de jogos. Essa diversidade de instrumentos avaliativos, possibilitou à educadora perceber os níveis das aprendizagens dos educandos e, ao mesmo tempo, aos educandos de desenvolver tarefas com níveis de aprofundamento diferenciados e objetivando desenvolver habilidades distintas. Para Rodrigues, 
a preocupação do professor da área das ciências humanas será a de preparar uma avaliação em que o aluno possa ir além da objetividade e, de sua parte, analisar os resultados de maneira crítica, refletindo sobre como os estudantes desenvolveram as subjetividades pretendidas (RODRIGUES, 2015, p. 133).

O mais gratificante e enriquecedor em todo o processo do uso das metodologias ativas e o ensino híbrido, foi poder constatar nos momentos de avaliação e autoavaliação, por meio das opiniões dos educandos, o entusiasmo e a curiosidade destes, em descobrir novos caminhos para alcançar o conhecimento e poder aprender de forma mais significativa. Trazendo os conceitos e processos históricos para uma realidade mais próxima da sua e perceber quanto a história faz parte do dia a dia e que, as relações existentes entre os fatos do passado influenciam diretamente o presente.

O que nos permite corroborar com a ideia de que a implantação da Educação 3.0 associada a novas formas da prática pedagógica e ao hibridismo podem aproximar a escola da realidade tecnológica vivida pelos educandos fora dela e adaptar-se dinamicamente as necessidades sociais e do mundo do trabalho advindas neste século.

\section{Referências}

BACICH, Lilian; TANZI NETO, Adolfo; TREVISANI, Fernando de Mello (org.). Ensino híbrido: personificação e tecnologia da educação. Porto Alegre: Penso, 2015.

BECKER, Fernando. Para uma pedagogia da ação e a Educação 3.0. In: CARVALHO, Mônica Timm de (org.). Educação 3.0: novas perspectivas para o ensino. São Leopoldo: Ed. UNISINOS; Porto Alegre: SINEPE, 2017, p. 25 a 44.

BERGMANN, Jonathan; SAMS, Aaron. Sala de aula invertida: uma metodologia ativa de aprendizagem. Rio de Janeiro: LTC, 2017.

BERLEZZI, Fernando L. C. Formação de professores de educação básica para uso de linguagem híbrida: a importância do roteiro de audiovisual no processo de ensino-aprendizagem. 2017. Dissertação (Mestrado) - Universidade Presbiteriana Mackenzie, São Paulo, 2017.

BITTENCOURT, Circe (org.) O saber histórico na sala de aula. 9. ed. São Paulo: Contexto, 2012. 
CARVALHO, Mônica Timm de (org.). Educação 3.0: novas perspectivas para o ensino. São Leopoldo: Ed. UNISINOS; Porto Alegre: SINEPE, 2017.

CAVALCANTE, Maria da Paz. Ensinar e aprender história na relação dialética entre interpretação e consciência histórica crítica. 2014. Tese (Doutorado) Universidade Federal do Rio Grande do Norte, Rio Grande do Norte, 2014.

CHARTIER, Roger. A história ou a leitura do tempo. Belo Horizonte: Autêntica, 2009.

ECCO, Idanir. O ensino de história: evidências e tendências atuais. Revista Ciências Humanas, Rio de Janeiro, v. 8, n. 10, p. 123-141, jun. 2007.

FREIRE, Paulo. Pedagogia da autonomia: saberes necessários à prática educativa. São Paulo: Paz e Terra, 1996.

GIL, Carmem Z. de Vargas; ALMEIDA, Dóris B. Práticas pedagógicas em história: espaço, tempo e corporeidade. Erechim: Edelbra, 2012.

HELENE, Daniel V. A história, seu ensino e sua aprendizagem: conhecimentos prévios e o pensar historicamente. 2016. Tese (Doutorado) - Universidade de São Paulo, São Paulo, 2016.

LENGEL, James G. A evolução da educação: 1-2-3. In: CARVALHO, Mônica Timm de (org.). Educação 3.0: novas perspectivas para o ensino. São Leopoldo: Ed. UNISINOS; Porto Alegre: SINEPE, 2017, p. 45 a 62.

LUCHESE, Terciane Ângela. Modos de fazer história da educação: pensando a operação historiográfica em temas regionais. História e Educação, Porto Alegre, v. 18 , n. 43, p. 145-161, maio/ago. 2014.

MARIA, Noemi A. O currículo e o ensino de história nos anos finais do ensino fundamental. 2012. Dissertação (Mestrado) - Universidade Federal do Rio Grande do Sul, Porto Alegre, 2012.

MARIN, Marilú Favarin; SCHMIDT, Maria Auxiliadora Moreira dos Santos. Relação teoria e prática na formação de professores de história: experiências de laboratórios de ensino no Brasil e da associação de professores de história em Portugal (1980-2010). In: ENCONTRO NACIONAL DOS PESQUISADORES DO ENSINO DE HISTÓRIA, 9., 2011. Florianópolis. Anais Eletrônicos [...]. Florianópolis: [UFSC], 2011.

MARTINS, Lilian C. B. Implicações da organização da atividade didática com uso de tecnologias digitais na formação de conceitos em uma proposta de ensino híbrido. 2016. Tese (Doutorado) - Universidade de São Paulo, São Paulo, 2016.

MORAN, José. Como transformar nossas escolas. In: CARVALHO, Mônica Timm de (org.). Educação 3.0: novas perspectivas para o ensino. São Leopoldo: Ed. UNISINOS; Porto Alegre: SINEPE, 2017, p. 63 a 91. 
MORAN, José. Educação híbrida: um conceito-chave para a educação, hoje. In: BACICH, Lilian; TANZI NETO, Adolfo; TREVISANI, Fernando de Mello (org.). Ensino híbrido: personificação e tecnologia da educação. Porto Alegre: Penso, 2015, p. 27 a 45 .

PINSKY, Carla Bassanezi (org.). Novos temas nas aulas de história. 2. ed. São Paulo: Contexto, 2010.

RODRIGUES, Eric Freitas. A avaliação e a tecnologia: a questão da verificação de aprendizagem no modelo de ensino híbrido. In: BACICH, Lilian; TANZI NETO, Adolfo; TREVISANI, Fernando de Mello (org.). Ensino híbrido: personificação e tecnologia da educação. Porto Alegre: Penso, 2015. p. 123 - 140.

SANTOS, Glauco de Souza. Espaços de aprendizagem. In: BACICH, Lilian; TANZI NETO, Adolfo; TREVISANI, Fernando de Mello (org.). Ensino híbrido: personificação e tecnologia da educação. Porto Alegre: Penso, 2015. p. 103 - 120.

SCHNEIDER, Fernanda. Otimização do espaço escolar por meio do modelo de ensino híbrido. In: BACICH, Lilian; TANZI NETO, Adolfo; TREVISANI, Fernando de Mello (org.). Ensino híbrido: personificação e tecnologia da educação. Porto Alegre: Penso, 2015. p. $67-80$.

SOARES, Eliana Maria Sacramento; LUCHESE, Terciane Ângela. A sala de aula no presente- passado: dois olhares, uma reflexão. Revista Intersaberes, Curitiba, v. 10, n. 21, set./dez. 2015.

YAMAMOTO, Iara. Metodologias ativas de aprendizagem interferem no desempenho de estudantes. 2016. Dissertação (Mestrado) - Universidade de São Paulo, São Paulo, 2016. 